\title{
Correction to: Corporatised Identities $\neq$ Digital Identities: Algorithmic Filtering on Social Media and the Commercialisation of Presentations of Self
}

\author{
Charlie Harry Smith
}

\section{Correction to:}

Chapter 3 in: C. Burr, L. Floridi (eds.), Ethics of Digital Well-Being, Philosophical Studies Series 140, https://doi.org/10.1007/978-3-030-50585-1_3

An earlier version of the chapter was published with an incorrect title by the publisher:

Corporatised Identities $\neq$ Digital Identities: Algorithmic Filtering on Social Media and the Commercialisation of Presentations of Self Corporatised.

It has now been corrected as follows:

Corporatised Identities $\neq$ Digital Identities: Algorithmic Filtering on Social Media and the Commercialisation of Presentations of Self. 